\title{
URINARY EXCRETION OF CHOLINE METABOLITES FOLLOW- ING CHOLINE ADMINISTRATION IN NORMALS AND PATIENTS WITH HEPATOBILIARY DISEASES ${ }^{1}$
}

\author{
By JESUS DE LA HUERGA 2 AND HANS POPPER
}

\author{
(From the Hektoen Institute for Medical Research and the Departments of Pathology of Cook \\ County Hospital and Northwestern University Medical School, Chicago, Ill.)
}

(Submitted for publication November 14, 1950 ; accepted, March 6, 1951)

Choline has been recommended for the treatment of hepatic diseases, especially those of nutritional origin, and for the prevention of arteriosclerosis. Little is known of its fate after oral or intravenous administration. A recent Spanish report (1) that patients with liver diseases and dogs with experimental hepatic damage excrete in the urine considerably more than normal of a substance precipitated by Reinecke salt (and considered as choline by the authors) after large doses of choline given orally, suggested that the utilization of choline might be altered in hepatobiliary disease. In addition, studies with radiophosphorous (2) indicate a reduced rate of phospholipid formation in the presence of hepatocellular damage and an increased rate in biliary obstruction, suggesting that less choline might appear in the urine than normal in obstructive jaundice and more than normal in liver cell damage.

To test these hypotheses and to investigate the fate of choline after its oral administration 1) the identity of the reineckate precipitated from the urine was determined, and 2) the influence upon its excretion of physiologic conditions as well as hepatobiliary diseases was studied.

\section{MATERIAL}

Four normal subjects and 22 patients with various hepatobiliary diseases were given on separate occasions single doses of choline bicarbonate ${ }^{3}$ equivalent to $2-8$ grams of choline base $(230-920 \mathrm{mg}$. choline $\mathrm{N})$. Their diets were not controlled. Urine samples, collected at various intervals, were preserved with $25 \mathrm{ml}$. of concentrated hydrochloric acid (diluted with equal parts of water) per liter of urine.

\footnotetext{
1 Supported by a grant from the Dr. Jerome D. Solomon Memorial Research Foundation.

2 Solomon Foundation Fellow.

3 We wish to thank Commercial Solvents Corporation for the generous supply of choline bicarbonate syrup.
}

\section{EXPERIMENTAL}

Chemical identification of the reineckate obtained from urines after choline administration and procedures applied for quantitative determination of the metabolites in the

$$
\text { urine }
$$

Reagents used:

1) Three per cent solution of Reinecke salt, freshly prepared and filtered.

2) Aqueous saturated solution of sodium hydroxide.

3) Aqueous saturated solution of potassium carbonate.

4) Folin and Ciocalteu reagent (3), diluted with three volumes of water before use.

5) Ten per cent aqueous solution of anhydrous sodium carbonate.

6) Choline reineckate: to $40 \mathrm{ml}$. of 1 per cent choline chloride $20 \mathrm{ml}$. of the Reinecke salt solution are added. After centrifugation the precipitate is washed three times with $20 \mathrm{ml}$. portions of water. The crystals are then dried at $37^{\circ} \mathrm{C}$. and stored. Immediately before use a saturated solution is freshly prepared by adding some of the choline reineckate to 0.1 normal sodium hydroxide, shaking and filtering.

7) Acetone, Norit A, Devarda's alloy, octyl alcohol, concentrated and 0.5 normal hydrochloric acid, normal and 0.1 normal sodium hydroxide.

The alkali-insoluble reineckate: The reineckate precipitated at a $\mathrm{pH}$ of 6.5 from urines after administration of choline (following the method of the Spanish authors [1]), was almost completely soluble in 0.1 normal sodium hydroxide. Since choline reineckate was found to be hardly soluble in this solution, the great bulk of the precipitate was not choline reineckate. On nitrogen basis, only $0.7 \mathrm{mg}$. of choline reineckate is soluble in $100 \mathrm{ml}$. of 0.1 normal sodium hydroxide while $113 \mathrm{mg}$. of urinary acid-precipitable reineckate are soluble in this solution. To determine the traces of alkali-precipitable reineckate (choline) the following procedure was used, adapted from the method of Glick (4).

Determination of choline: Saturated sodium hydroxide is added to $70 \mathrm{ml}$. of urine until a blue color to thymolphthalein appears. The precipitate is removed by filtration and to an aliquot, representing $50 \mathrm{ml}$. of urine, 25 ml. of Reinecke salt solution are added. The Reinecke precipitate formed in four hours in the refrigerator is spun 
TABLE I

Recovery of choline added to urine with the method used

\begin{tabular}{l|c|c|c}
\hline \hline Diagnosis & $\begin{array}{c}\text { Mg. choline } \\
\text { N added to } \\
100 \mathrm{ml} .\end{array}$ & $\begin{array}{c}\text { Mg. choline } \\
\text { N found per } \\
\text { 100 ml. }\end{array}$ & $\begin{array}{c}\text { Per cent } \\
\text { choline N } \\
\text { recovered }\end{array}$ \\
\hline Normal & 0.250 & 0.240 & 96 \\
& 0.750 & 0.710 & 93 \\
& 1.250 & 1.280 & 102 \\
Hepatitis & 0.250 & 0.220 & 88 \\
& 0.750 & 0.740 & 98 \\
& 1.250 & 1.360 & 107 \\
\hline
\end{tabular}

down. It is washed with the saturated solution of choline reineckate in order to remove any co-precipitated noncholine reineckate. The final residue is dissolved in acetone containing 1 per cent glacial acetic acid. The solution is filtered if necessary and made to a noted volume. The transmittancy is read in a spectrophotometer or colorimeter at a wave length of $520 \mathrm{~m} \mu$. A standard curve is made with choline chloride using the same procedure. The results are calculated in $\mathrm{mg}$. of choline $\mathrm{N}$ per $\mathrm{ml}$. of the acetone reineckate solution. Choline added to urines from normal or hepatitis patients was recovered quantitatively (Table I). The amount demonstrated by this method represented in the studied cases 0.22 to 4.40 per cent of the total reineckate in the 24-hour urine and 0.27 to 1.04 per cent of the total amount of the choline $\mathrm{N}$ ingested.

The alkali-soluble reineckate: To demonstrate whether the alkali-soluble reineckate represents one of the recognized metabolites of choline such as betaine, dimethylamine or trimethylamine or its oxide, the reineckate precipitated from $10 \mathrm{ml}$. of acidified urine from normals and from patients suffering from hepatic diseases after administration of choline was dissolved in $20 \mathrm{ml}$. of 50 per cent aqueous acetone. Then $5 \mathrm{ml}$. of aqueous saturated silver sulfate solution were added (5) to remove the Reinecke ion. In the filtrate, the excess silver was removed with $5 \mathrm{ml}$. of normal hydrochloric acid and the water clear filtrate was evaporated under partial vacuum and under nitrogen at $30^{\circ} \mathrm{C}$. The residue was dissolved in $10 \mathrm{ml}$. of methyl alcohol, filtered and evaporated as above. The final residue was dissolved in $20 \mathrm{ml}$. of water. An aliquot $(10 \mathrm{ml}$.) was alkalinized with potassium carbonate and aerated for two hours at room temperature in the apparatus described by Sobel and associates (6) into $5 \mathrm{ml}$. of 0.5 normal hydrochloric acid. To this, $3 \mathrm{ml}$. of Reinecke salt solution were added and the crystalline precipitate obtained showed the microscopic appearance and melting point $\left(275^{\circ}\right.$ C. $)$ characteristic of trimethylamine reineckate. Mixing of the crystalline precipitate with trimethylamine reineckate did not alter the melting point. The melting point of the picrate was $216^{\circ} \mathrm{C}$., identical with that of trimethylamine picrate and was also not altered by mixing with trimethylamine picrate.

To investigate whether trimethylamine oxide (TMAO) was also present in addition to trimethylamine (TMA) (the former not being aerated under the experimental conditions used), another aliquot of $10 \mathrm{ml}$. was acidified with hydrochloric acid to normality. It was then reduced with 0.5 gram of Devarda's alloy and placed in a water bath at $90^{\circ}$ to $95^{\circ} \mathrm{C}$. for 40 minutes. After centrifugation the supernatant was transferred to the aerating apparatus and enough saturated sodium hydroxide was added to redissolve the precipitate formed and then $3 \mathrm{ml}$. of saturated potassium carbonate were added. The mixture was aerated as before. In four experiments (two normal subjects and two patients with cirrhosis), the TMAO accounted for 90 to 97 per cent of the total reineckate, TMA for 5 to 10 per cent and choline for 0.56 to 0.77 per cent.

Determination of total trimethylamines (TTMA) with Reinecke salt: To $50 \mathrm{ml}$. of acid urine about 2 grams of Norit $\mathbf{A}$ are added and the mixture shaken and allowed

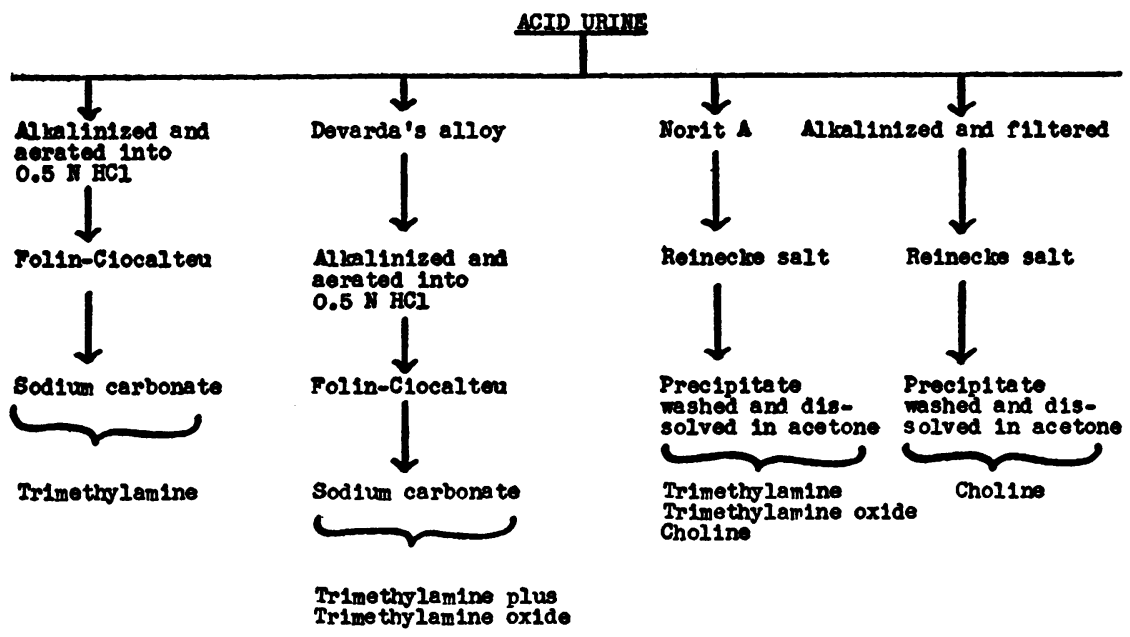

Fig. 1. Analytical Scheme for the Quantitative Determination of Choline, Trimethylamine and Trimethylamine Oxide 


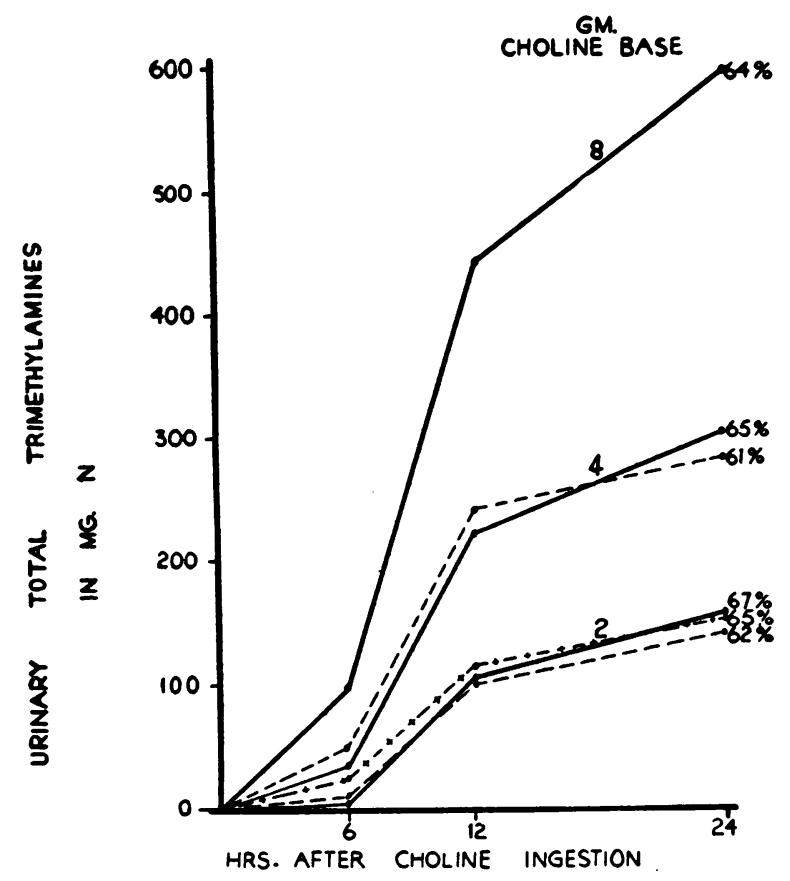

Fig. 2. Urinary Excretion of Trimethylamines by Normal Persons after Oral Administration of Various Amounts of Choline

The percentage refers to the amount of trimethylamine $\mathrm{N}$ in relation to choline $\mathrm{N}$ administered. Each type of line refers to the same experimental subject.

to stand for at least 30 minutes. In some concentrated urines it is necessary to dilute the Norit filtrate. To 5 or $10 \mathrm{ml}$. of the filtrate, half a volume of the Reinecke salt solution is added. The crystalline precipitate obtained after standing at $10^{\circ} \mathrm{C}$. for one hour is collected onto a fine sintered glass filter using vacuum and washed with saturated aqueous solution of "urine acid-precipitable reineckate," prepared from the same urine. The error produced by using a saturated solution of the reineckate does not exceed 20 micrograms and is, therefore, negligible. The crystals are then dissolved in acetone. The color is read in the spectrophotometer as in the determination of choline. The extinction co-efficient of the Reinecke salt of TMAO (prepared according to Dunstand and Goulding [7]), was found to be the same as that of choline, betaine and TMA chlorides when expressed as nitrogen. The very small amount of choline determined with TTMA can be ignored. The presence of betaine or other quaternary ammonium bases was excluded because the reineckate precipitable material was shown to be quantitatively removed by reduction and aeration.

Use of Folin-Ciocalteu reagent: The quantitative relation between TMA and TMAO was investigated by determining with the Folin-Ciocalteu reagent the TMA in the aerates from alkalinized urines with and without previous reduction. This reagent, otherwise used for the determination of phenols, gives a blue color with TMA (8) but not with ammonium, mono- or dimethylamine salts. Since the phenols of the urine are not aerated under the experimental conditions, the color reaction can be considered specific for TMA. This offers an alternative and simple method for the determination of TTMA even if present in small amounts. This method which has been used in this study for the determination in the stool cultures has subsequently been proven applicable for urine specimens.

Method for determination of trimethylamines with the Folin-Ciocalteu reagent: For determination of TMA, 10 $\mathrm{ml}$. of urine are neutralized with saturated sodium hydroxide, followed by addition of $3 \mathrm{ml}$. of saturated potassium carbonate and 4 or 5 drops of octyl alcohol. The mixture is aerated and the TMA is collected as described before. An aliquot is neutralized with normal sodium hydroxide and made to $5 \mathrm{ml}$. with water; $2 \mathrm{ml}$. of FolinCiocalteu reagent and $3 \mathrm{ml}$. of the sodium carbonate solutions are added. After 15 minutes the developed color is read in a spectrophotometer at $620 \mathrm{~m} \mu$. A standard curve is made with pure, dried TMA hydrochloride. For determination of TTMA, $10 \mathrm{ml}$. of urine are mixed with enough concentrated hydrochloric acid to make it normal. The sample is treated with Devarda's alloy as previously described, to reduce TMAO to TMA (9). After cooling, saturated sodium hydroxide solution is added until the precipitate formed re-dissolves. Now $3 \mathrm{ml}$. of saturated po- 
TABLE II

Urinary excretion of choline and trimethylamines in normal individuals within 24 hours after administration of 2 grams choline base

\begin{tabular}{l|c|c|c|c|c}
\hline \hline \multicolumn{2}{c|}{ Choline } & \multicolumn{4}{|c}{ Total trimethylamines } \\
\cline { 2 - 5 } Mg. N & $\begin{array}{c}\text { Per cent } \\
\text { of choline } \\
\text { N fed }\end{array}$ & Mg. N & $\begin{array}{c}\text { Per cent } \\
\text { of choline } \\
\text { N fed }\end{array}$ & $\begin{array}{c}\text { Per cent } \\
\text { excreted } \\
\text { in first } \\
12 \text { hours }\end{array}$ & $\begin{array}{c}\text { (Choline/ } \\
\text { TMA) } \\
\text { X100 }\end{array}$ \\
\hline 1.20 & 0.53 & 155.0 & 67.0 & 67.5 & 0.77 \\
0.80 & 0.35 & 142.3 & 61.8 & 70.2 & 0.56 \\
0.90 & 0.39 & 150.0 & 65.0 & 77.0 & 0.60 \\
0.75 & 0.33 & 138.2 & 60.0 & 65.5 & 0.54 \\
\hline
\end{tabular}

tassium carbonate are added and the sample is aerated as before. The aerate is conveniently diluted and treated with the Folin-Ciocalteu reagent. TMAO is calculated from the difference between the values before and after reduction. Choline and betaine are not converted into TMA and, therefore, fail to give the reaction.

The principles of the procedures applied are illustrated in Figure 1.

\section{Variations of urinary choline and TTMA excretion under physiologic conditions}

Excretion under basal conditions: In four normal subjects and seven patients with liver disease, no choline was demonstrated in 24-hour specimens of urine. In four normal subjects, 5.70 to 11.00 mg. of TTMA N and in 22 patients with liver dis-

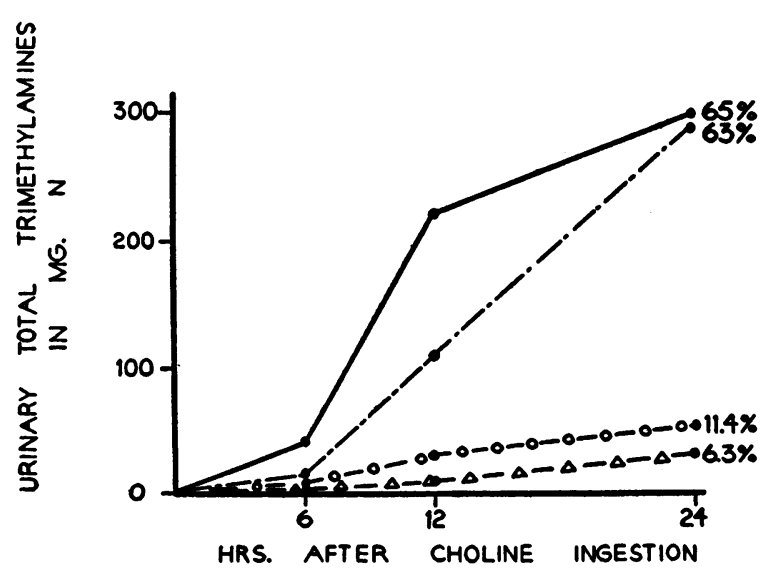

Fig. 3. Urinary Excretion of Trimethylamines after Oral Administration of 4 Grams of Choline Base to a Normal Person without Supplement ( $)$, after Four Days Treatment with AUREOMYCIN AND SUlfathalidine (-O-O-), with Simultaneous Administration of 100 Grams Cane Sugar (-.- - ) ANd 100 Grams of Starch $(-\Delta-\Delta-)$

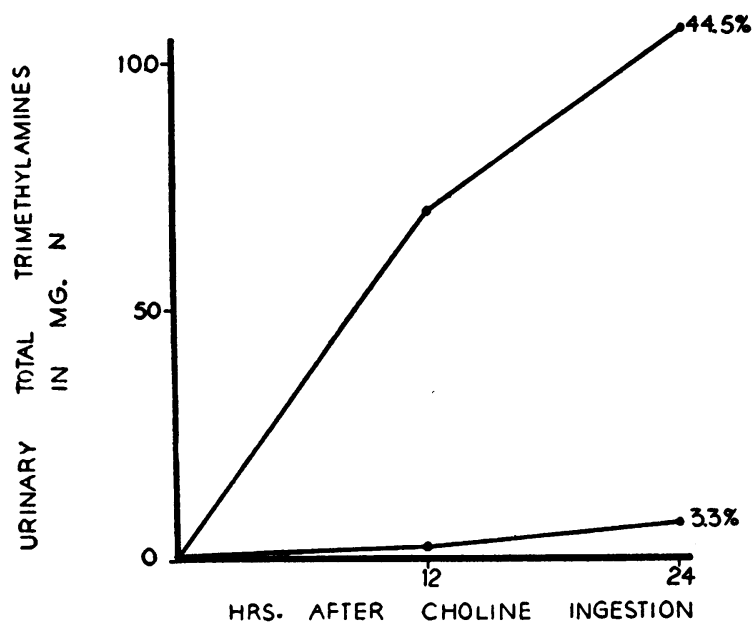

Fig. 4. Urinary Excretion of Trimethylamines by a Patient with Hepatic Cirrhosis after Oral Administration of 2 Grams Choline Base before (UPper Line) and after (Lower Line) Four Days Treatment with Aureomycin and Sulfathalidine

ease, 5.80 to $14.99 \mathrm{mg}$. of TTMA $\mathrm{N}$ were found in 24-hour specimens of urine.

Response to administration of choline: After administration of 8 grams of choline base to one normal individual, equal quantities of choline were excreted in any period observed. During the first 24 hours the total excretion was $1.40 \mathrm{mg}$. choline

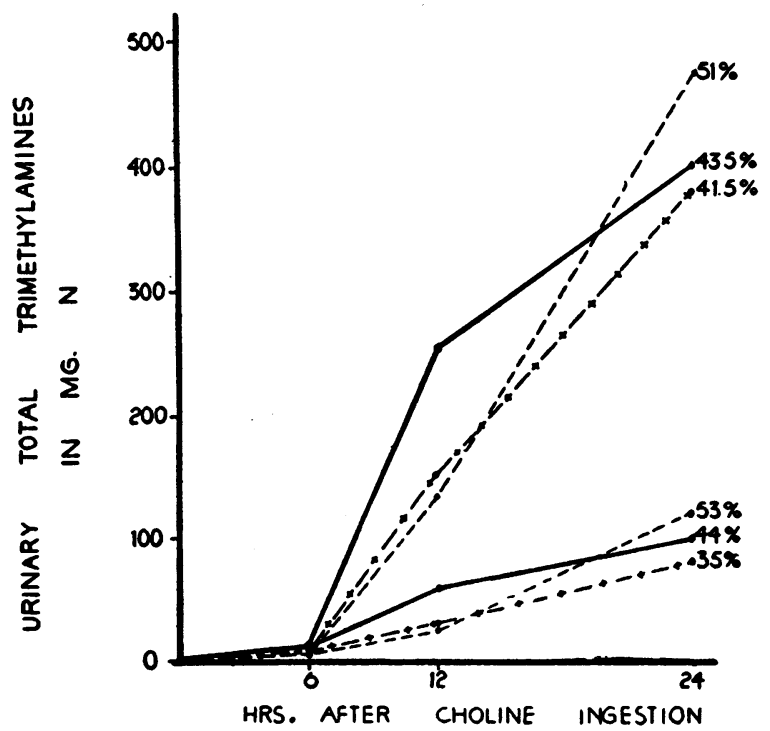

Fig. 5. URINARY Excretion OF Trimethylamines BY Three Patients with Liver Disease after Administration of 8 Grams (UPPER LiNe) aNd 2 Grams (Lower line) Choline Base

Each type of line refers to the same patient. 
N. Upon administration of 2 or 4 grams of choline base to four normal individuals, 0.75 to 1.60 mg. choline $\mathrm{N}$ were excreted in the urine. After administration of 2 to 8 grams of choline base to four normal subjects (in six experiments [Figure 2]), 60 to 67 per cent of choline $N$ was excreted within 24 hours as TTMA of which 95 to 97 per cent was TMAO. This percentage was independent of the amount administered. Relatively little was excreted before six hours and after 12 hours, the bulk being excreted between six and 12 hours (Table II).

Effect of ingestion of other methyl compounds: Administration of 4 and 8 grams of betaine chloride or of 20 grams of dl-methionine to a normal individual did not cause urinary excretion of either choline or betaine and did not increase TTMA excretion.

Influence of intestinal bacteria upon the excretion of TTMA: Since previous investigations (10) indicated that choline is metabolized to TMA by species of the genera Proteus, Salmonella, Eberthella and Shigella, the TMA formation was deter- mined by the aeration method in tryptose media which contained 1 per cent of choline chloride and had been inoculated with 1 drop of $1: 1,000$ saline dilution of feces. In five samples, 41 to 60 per cent of the choline present was converted to TMA in 24 hours. If 0.3 gram or less choline chloride was present in $100 \mathrm{ml}$. of tryptose medium, all choline was converted to TMA. The urinary excretion of TTMA was determined in one normal person and in two patients with cirrhosis of the liver before and after administration of 0.5 gram of aureomycin and 1 gram of sulfathalidine every four hours for four days including the day of the second choline administration. In all three instances the excretion of TTMA was greatly reduced (Figures 3 and 4 representing two of the instances). In the third one (a patient with cirrhosis) only 12 -hour urine collections were available and $17.1 \mathrm{mg}$. of TTMA $\mathrm{N}$ instead of 78.5 mg. (without antimicrobial treatment) were excreted. Feces of the experimental subjects after treatment with aureomycin and sulfathalidine proved to be almost free of bacteria.

TABLE III

Urinary excretion of choline and trimethylamines in patients with hepatobiliary diseases within 24 hours after administration of 2 grams of choline base

\begin{tabular}{|c|c|c|c|c|c|c|}
\hline \multirow[b]{2}{*}{ Diagnosis } & \multicolumn{2}{|c|}{ Choline } & \multicolumn{4}{|c|}{ Total trimethylamines } \\
\hline & $\mathbf{M g} \cdot \mathbf{N}$ & $\begin{array}{l}\text { Per cent } \\
\text { of choline } \\
\mathrm{N} \text { fed }\end{array}$ & $\mathbf{M g} \cdot \mathbf{N}$ & $\begin{array}{l}\text { Per cent } \\
\text { of choline } \\
\mathbf{N} \text { fed }\end{array}$ & $\begin{array}{l}\text { Per cent } \\
\text { excreted } \\
\text { in first } \\
12 \text { hours }\end{array}$ & $\underset{\times 100}{\text { (Choline/TMA) }}$ \\
\hline $\begin{array}{l}\text { Obstruct. jaundice } \\
\text { Obstruct. jaundice } \\
\text { Obstruct. jaundice } \\
\text { Infect. hepatitis } \\
\text { Infect. hepatitis } \\
\text { Infect. hepatitis } \\
\text { Infect. hepatitis } \\
\text { Infect. hepatitis } \\
\text { Chronic hepatitis } \\
\text { Chronic hepatitis } \\
\text { Cirrhosis } \\
\text { Cirrhosis } \\
\text { Cirrhosis } \\
\text { Cirrhosis with jaundice } \\
\text { Cirrhosis with jaundice } \\
\text { Cirrhosis with jaundice } \\
\text { Cirrhosis with ascites } \\
\text { Cirrhosis with jaundice and } \\
\text { ascites } \\
\text { Cirrhosis with jaundice and } \\
\text { ascites } \\
\text { Cirrhosis with jaundice and } \\
\text { ascites } \\
\text { Cirrhosis with jaundice and } \\
\text { ascites } \\
\text { Cirrhosis with jaundice and } \\
\text { ascites }\end{array}$ & $\begin{array}{l}1.40 \\
1.30 \\
0.79 \\
2.38 \\
1.18 \\
0.75 \\
0.62 \\
1.90 \\
0.31 \\
0.59 \\
0.70 \\
0.77 \\
1.10 \\
1.02 \\
0.65 \\
1.35 \\
1.15 \\
- \\
1.02 \\
0.85\end{array}$ & $\begin{array}{l}0.65 \\
0.56 \\
0.34 \\
1.04 \\
0.51 \\
0.35 \\
0.27 \\
0.83 \\
0.13 \\
0.26 \\
0.30 \\
0.34 \\
0.48 \\
0.44 \\
0.28 \\
0.59 \\
0.65 \\
- \\
0.44 \\
0.37\end{array}$ & $\begin{array}{r}152.0 \\
77.1 \\
140.0 \\
61.0 \\
106.0 \\
148.1 \\
101.4 \\
91.7 \\
144.1 \\
122.4 \\
106.8 \\
87.9 \\
80.2 \\
28.6 \\
25.0 \\
80.5 \\
101.0 \\
82.5 \\
26.2 \\
25.6 \\
82.1 \\
49.5\end{array}$ & $\begin{array}{l}66.0 \\
33.6 \\
60.5 \\
26.5 \\
46.0 \\
64.0 \\
44.2 \\
39.8 \\
63.0 \\
53.0 \\
45.5 \\
38.2 \\
35.0 \\
12.4 \\
10.9 \\
35.0 \\
44.0 \\
35.8 \\
11.4 \\
\\
11.2 \\
35.7 \\
21.5\end{array}$ & $\begin{array}{r}46.0 \\
41.5 \\
67.0 \\
36.0 \\
55.0 \\
31.0 \\
9.2 \\
13.2 \\
24.7 \\
20.3 \\
70.0 \\
33.1 \\
34.2 \\
42.0 \\
72.0 \\
38.0 \\
29.5 \\
61.0 \\
61.0 \\
39.0 \\
39.4 \\
18.2\end{array}$ & $\begin{array}{l}0.92 \\
1.70 \\
0.56 \\
3.80 \\
1.12 \\
0.51 \\
0.61 \\
2.08 \\
0.22 \\
0.48 \\
\overline{0.79} \\
0.96 \\
3.85 \\
4.00 \\
0.64 \\
1.64 \\
4.40 \\
- \\
1.22 \\
1.73\end{array}$ \\
\hline
\end{tabular}


It has been shown that glucose inhibits the conversion of choline to TMA by bacteria (10). Tryptose-choline media to which 1 per cent of glucose was added, failed to reveal upon inoculation with fecal material, any TMA formation. One normal subject who received simultaneously with 4 grams of choline base, 100 grams of cane sugar, excreted in the first 12 hours half of the TMA excreted previously without sugar adminisrtation; after 24 hours the excretion did not differ from the previous test (Figure 3 ).

Administration of 100 grams of starch simultaneously with choline decreased the TTMA excretion in one normal person (after ingestion of 4 grams of choline base) to one-tenth, even after 24 hours (Figure 3 ). In a second instance (which is not graphically presented), the TTMA excretion after administration of 2 grams of choline base decreased following starch intake from 61 to 17.4 per cent of the choline $\mathrm{N}$ given. The urinary choline excretion did not increase.

\section{Excretion of choline and TTMA in patients with liver diseases}

In patients with liver diseases the urinary excretion of choline after administration of 2 grams of choline base was not higher than in normals. In the three patients who received 8 grams of choline base, the amount of choline excreted was higher (between 2.6 and $3.4 \mathrm{mg}$. choline $\mathrm{N}$ ) but did not exceed one-third of 1 per cent of the total amount given.

After administration of 2 grams of choline base, two out of three patients with obstructive jaundice had a normal excretion of TTMA while the third, who died a few days later, excreted considerably less. Of seven patients with infectious hepatitis, five excreted considerably less TTMA than normal. In all 10 cases of cirrhosis investigated (two studied twice), the excretion was markedly decreased; in the two instances studied on two occasions, almost identical results were obtained. Moreover, in almost all patients with hepatic disease, the excretion was delayed in contrast to the normals. In the latter, the bulk of TTMA was excreted in the first 12 hours after the intake of choline while in the patients it was excreted between 12 and 24 hours. This delay was apparent even if the total amount excreted per 24 hours was not significantly decreased (Table III).

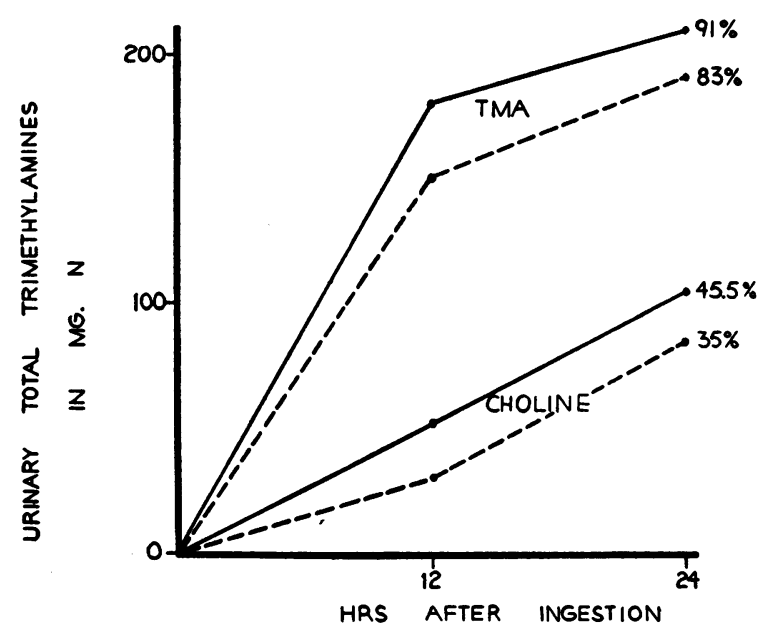

Fig. 6. Urinary Excretion of Trimethylamines after Administration of Choline Bicarbonate and Trimethylamine Hydrochloride (Both in Amounts of 230 Mg. N) by Two Patients with Hepatic CirRHOSIS

Each type of line refers to the same patient.

In three patients with liver disease, the percentage of TTMA $\mathrm{N}$ excreted in relation to the amount of choline $\mathrm{N}$ ingested was not significantly changed when 8 grams instead of 2 grams of choline base were given (Figure 5). Two patients with liver disease who previously had delayed and reduced TTMA excretion after choline administration and who ingested TMA hydrochloride in amounts equivalent to $230 \mathrm{mg}$. $\mathrm{N}$ excreted it rapidly and almost completely (Figure 6).

\section{DISCUSSION}

In contradiction to the previously cited report on urinary choline excretion (1), this substance is excreted in the urine in insignificant amounts by normal subjects and patients with liver diseases with or without administration of large doses of choline. With the method used, the excretion rarely exceeded one-third of 1 per cent of the administered dose. Moreover, reasonable doubt exists as to whether the very small precipitate represents choline and the figures given are maximum rather than actual amounts. The bulk of the reineckate obtained in the urine after choline administration (independent of the quantity administered) was proven to be trimethylamine (TMA). The greatest part of TMA was in the oxide form. This is in keeping with previous reports that in 
rats (11) and in one human (12) after choline administration, TMA and TMAO appeared in the urine.

This study indicates that, as measured by two different methods, two-thirds of the choline administered appears in the urine as TMA or its oxide. The absolute amount is astonishingly well duplicated in the same person. . Since many bacteria, especially those of the Proteus and Shigella groups, are known to transform choline into TMA (10), the possibility of such a process in the intestinal tract had to be considered. It was confirmed by the observation that in vitro feces transform choline, to a large degree, to TMA and that suppression of the intestinal flora by antimicrobial agents greatly inhibits the urinary total trimethylamines (TTMA) excretion without influence upon the choline excretion. The conclusion is justified that two-thirds of choline administered as dietary supplement, independent of the dose given, is transformed in the intestinal tract into TMA. Information as to the lipotropic activity of the latter is not available. Neither betaine nor methionine is transformed or excreted as TTMA. The fate of the remaining one-third of choline in the body is unknown.

The concept of an extensive bacterial transformation of choline into TMA appears strange in view of the fact that choline absorption should take place in the upper part of the small intestine while significant bacterial activity starts in the large intestine. Further investigations should clarify the extent of absorption of choline as such in different species.

Glucose, which is known to suppress TMA production from choline by bacteria, inhibits in vitro production of TMA by feces. Therefore, the suppression of intestinal TMA formation (as measured by urinary TTMA excretion) by administration of choline together with carbohydrates was attempted. Cane sugar, which is rapidly absorbed from the intestine, delayed the TTMA excretion (and probably the bacterial transformation) without reducing the total excretion in 24 hours. In contrast, starch given with choline for the entire 24-hour period considerably depressed the bacterial transformation of choline if the urinary excretion of TTMA is a measurement.

Three possible explanations have to be considered for the observed reduction or delay of the uri- nary TTMA excretion after choline intake found in hepatic diseases :

(a) Impaired absorption of TMA in the presence of liver damage. The almost complete urinary excretion of ingested TMA even in patients with liver disease speaks against this assumption.

(b) Faulty urinary excretion of TTMA. The complete excretion of fed TMA in liver diseases contradicts this possibility also. The bulk of TMA is excreted as its oxide. The possibility, therefore, has to be considered that. the oxidized form is more readily eliminated by the kidneys; if the liver performs this oxidation, in liver diseases this function could be at fault. In vitro studies (13) have indicated that liver tissue reduces TMAO to TMA; therefore, the fact that the ratio between urinary TMA and TMAO is not significantly altered in liver diseases contradicts this assumption.

(c) Faulty bacterial action in liver diseases. Possibly the bacterial flora of the intestine is altered in patients with hepatobiliary diseases in a quantitative and/or qualitative manner which might explain the reduced formation of TMA in these conditions.

The data so far available are too scant to permit conclusions about the therapeutic value of supplementing choline therapy with antimicrobial agents or carbohydrates or about the causes of choline deficiency in the human. The utilization of orally administered choline as measured by phospholipid turnover with $\mathrm{P}^{32}$ (14) cannot, at present, be correlated with the urinary excretion of TTMA since the latter does not reflect the fate of absorbed choline in the body. For this purpose, studies on the urinary excretion of intravenously administered choline, which are at present under way, appear more promising.

\section{SUMMARY}

1. A procedure was adopted for the determination of choline in the urine using its precipitation by Reinecke salt, and procedures were developed for the determination of trimethylamine and trimethylamine oxide in the urine, based on either Reinecke salt precipitation or on the Folin-Ciocalteu reaction. These procedures were applied to the urines of four normal persons and 22 patients with hepatobiliary diseases before and after oral administration of 2 to 8 grams of choline base. 
2. Choline was not found in the urines of normal persons nor patients with hepatobiliary diseases under basal conditions. After oral administration of choline, very small amounts, if any, of choline were excreted, as a rule not exceeding 0.3 per cent of the amount of choline administered.

3. Under basal conditions, small amounts of trimethylamines were found in the urine. Within 24 hours about two-thirds of the choline $\mathrm{N}$ ingested was excreted in normal individuals as trimethylamine and its oxide.

4. Incubated stool dilutions transformed choline to trimethylamine. Inhibition of the intestinal flora by aureomycin and sulfathalidine greatly depressed the urinary trimethylamine excretion. This suggests that the urinary trimethylamines result from bacterial transformation of choline in the intestine. The greater part of therapeutically administered choline is, therefore, changed in the liver into a product without known lipotropic activity.

5. Administration of cane sugar with choline delayed urinary trimethylamine excretion, while intake of starch depressed it.

6. In liver diseases the urinary trimethylamine elimination after choline administration is delayed or decreased. Ingested trimethylamine in these patients is readily excreted.

\section{REFERENCES}

1. Castro-Mendoza, H., Jimenez, D. C., and del Rio S. J., La eliminación urinaria de colina (espontánea y por sobrecarga) en los sujetos normales y en los enfermos del higado. Rev. clín. españ., 1948, 28, 295.

2. Balfour, W. M., Human plasma phospholipid formation: a study made with the aid of radiophosphorus. Gastroenterology, 1947, 9, 686.
3. Folin, O., and Ciocalteu, V., On tyrosine and tryptophane determinations in proteins. J. Biol. Chem., 1927, 73, 627.

4. Glick, D., Concerning the reineckate method for the determination of choline. J. Biol. Chem., 1944, 156, 643.

5. Kapfhammer, J., and Bischoff, C., Acetylcholin und Cholin aus tierischen Organen. I. Darstellung aus Rinderblut. Ztschr. f. physiol. Chem., 1930, 191, 179.

6. Sobel, A. E., Mayer, A. M., and Gottfried, S. P., A convenient titrimetric ultramicromethod for the estimation of urea and Kjeldahl nitrogen. J. Biol. Chem., 1944, 156, 355.

7. Dunstan, W. R., and Goulding, B., The action of hydrogen peroxide on secondary and tertiary aliphatic amines. Formation of hydroxylamines and of oxamines. J. Chem. Soc., 1898, 75, 1004.

8. Dyer, W. J., Amines in fish muscle: I. Colorimetric determination of trimethylamine as the picrate salt. J. Fisheries Research Board, Canada, 1945, 6, 351.

9. Norris, E. R., and Benoit, G. J., Jr., Studies on trimethylamine oxide. I. Occurrence of trimethylamine oxide in marine organisms. J. Biol. Chem., 1945, 158, 433.

10. Dyer, F. E., and Wood, A. J., Action of Enterobacteriaceae on choline and related compounds. J. Fisheries Research Board, Canada, 1947, 7, 17.

11. Norris, E. R., and Benoit, G. J., Jr., Studies on trimethylamine oxide. III. Trimethylamine oxide excretion by the rat. J. Biol. Chem., 1945, 158, 443.

12. Lintzel, W., Untersuchungen über Trimethylammoniumbasen. III. Trimethylammoniumbasen im menschlichen Harn. Biochem. Ztschr., 1934, 273, 243.

13. Müller, H., Uber den Cholinstoff wechsel. II. Mitteilung. Ztschr. f. physiol. Chem., 1940, 226, 205.

14. Cayer, D., and Cornatzer, W. E., The effects of lipotropic substances on phospholipide synthesis in patients with and without chronic hepatitis as measured by radioactive phosphorus. Southern Med. J., 1949, 42, 669. 